\title{
Development of low-fat mayonnaise containing polysaccharide gums as functional ingredients
}

\author{
Hou-Pin $\mathrm{Su}^{\mathrm{a}}{ }^{\mathrm{C}}$ Chuang-Ping Lien, ${ }^{\mathrm{a}}$ Tan-Ang Lee ${ }^{\mathrm{b}}$ and Ruo-Syuan Ho ${ }^{\mathrm{c} *}$
}

\begin{abstract}
BACKGROUND: The objective of this study was to develop a low-fat (LF) mayonnaise containing polysaccharide gums as functional ingredients. Xanthan gum (XG, $15 \mathrm{~g} \mathrm{~kg}^{-1}$ ), citrus fiber (CF, $100 \mathrm{~g} \mathrm{~kg}^{-1}$ ) and variable concentration of guar gum (GG) were used to formulate the optimum ratios of polysaccharide gums as fat replacers. The fat content in LF mayonnaise was reduced to $50 \%$ if compared with full-fat (FF) mayonnaise, and the products still maintained ideal rheological properties.

RESULTS: The rheological parameters showed that there were no $(P>0.05)$ differences in yield stress, viscosity and flow behavior index between XG $+10 \mathrm{~g} \mathrm{~kg}^{-1} \mathrm{GG}, \mathrm{CF}+5 \mathrm{~g} \mathrm{~kg}^{-1} \mathrm{GG}$ and FF control. LF mayonnaises had lower caloric values and higher dietary fiber content than the FF counterpart. Scanning electron microscopy (SEM) micrographs illustrated that the network of aggregated droplets in LF treatments contained a large number of interspaced voids of varying dimensions. Furthermore, in a comparison of sensory evaluation of LF treatments with commercial and our FF mayonnaises, there were no $(P>0.05)$ differences in any sensory scores among XG $+10 \mathbf{g ~ k g}^{-1} \mathbf{G G}$ control.
\end{abstract}

CONCLUSION: This study shows that XG $+10 \mathrm{~g} \mathrm{~kg}^{-1} \mathrm{GG}$ and CF $+5 \mathrm{~g} \mathrm{~kg}^{-1} \mathrm{GG}$ could be used in LF mayonnaise formulations based on its multiple functions on processing properties.

(c) 2010 Society of Chemical Industry

Keywords: low-fat mayonnaise; polysaccharide gums; xanthan gum; guar gum; citrus fiber; rheological properties

\section{INTRODUCTION}

Mayonnaise is a common food product worldwide. It is traditionally prepared by using egg yolk or the whole egg to emulsify a large amount of oil. The oil content of traditional mayonnaise is more than $65 \%{ }^{1}$ hence it is generally regarded as a high-fat and high-caloric food. At the same time, a positive relationship between dietary fat and development of cardiovascular diseases, hypertension and obesity was reported previously, thus decreasing consumption of low-fat or low-energy products. ${ }^{2}$ Hence a development of low-fat (LF) mayonnaise is an important issue not only for the food industry but also for consumers. As a component of mayonnaise, fat contributes to the flavor, appearance, texture, and shelf-life. When developing LF mayonnaise, it is difficult to imitate the qualities of traditional mayonnaise. Generally, nonfat ingredients such as gums, starches, and proteins with different functionalities are incorporated into fat-reduced products. Many of these result in loss of quality and attributes in LF products compared to full-fat (FF) products. ${ }^{3}$

It is expected that a new fat replacer will not only improve processing functionalities but also contribute to nutritional benefits. For example, polysaccharide gels containing considerable dietary fiber are good substitutes for fat. ${ }^{4,5}$ Polysaccharide gels, including pectin, guar gum (GG) and xanthan gums (XG), have been increasingly studied as fat replacers in food processing, e.g. in LF meat products. However, few reports focus on reduced-fat mayonnaise. ${ }^{6,7}$ Rheological properties quantitatively contribute to texture characteristics; hence they are often applied to study the influence of texture in different formulations of mayonnaise. ${ }^{8,9}$ $X G$ is one of the polysaccharide gums often used in mayonnaise alone, or together with other gums in salad dressings, to produce the desired rheological properties. ${ }^{5,10}$ In addition, citrus fiber (CF) is used as a fat replacer, stabilizer and emulsifier in ice cream processing, but does not affect the viscosity, overrun or sensory properties of ice cream. ${ }^{11}$

There are no reports related to the application of natural dietary fibers as fat replacers in LF mayonnaise, nor a complete investigation of its rheological and texture properties. Therefore, this study investigated the effects of XG and CF in combination with GG as fat replacers in different mayonnaise formulations by detecting their physicochemical, rheological and sensory properties.

* Correspondence to: Ruo-Syuan Ho, Department of Nutrition and Health Science, Toko University, No. 51, Sec. 2, Hsueh Fu Rd, Pu-Tzu, Chia-Yi, Taiwan 613,ROC.E-mail:tingting@mail.toko.edu.tw

a Department of Animal Science and Technology, National Taiwan University, Taipei, Taiwan 106, ROC

b Department of Animal Science and Biotechnology, Tunghai University, Taichung, Taiwan 407, ROC

c Department of Nutrition and Health Science, Toko University, Chia-Yi, Taiwan $613, R O C$ 
Table 1. Formulations of full-fat and low-fat mayonnaises

Full fat mayonnaise Low-fat mayonnaise $\left(\mathrm{g} \mathrm{kg}^{-1}\right)$ $\left(\mathrm{g} \mathrm{kg}^{-1}\right)$

\begin{tabular}{lcc|}
\hline Egg yolk & 140.5 & 140.5 \\
Soybean oil & 730 & 365 \\
polysaccharide gums & 0 & 365 \\
Vinegar & 92 & 92 \\
Sugar & 27 & 27 \\
Salt & 10.8 & 10.8
\end{tabular}

\section{MATERIALS AND METHODS}

\section{Materials}

XG and CF were purchased from Dah Chung Trading Co., Taiwan. GG was provided by Gemfont Co., Taiwan. Other ingredients for the experimental mayonnaises, such as egg, apple vinegar, salt, sugar and soybean oil, were purchased from a local supermarket. All chemicals were of analytical grade (extra pure).

\section{Preparation of the fat replacers}

There were three kinds of polysaccharide gum used as fat replacers in this study. First, XG and CF were dissolved in deionized water, which was adjusted to concentrations of 15 and $100 \mathrm{~g} \mathrm{~kg}^{-1}$, respectively. The XG-GG mixture was formed by mixing the XG gel $\left(15 \mathrm{~g} \mathrm{~kg}^{-1}\right)$ with $0,5.0,7.5,10.0$ or $12.5 \mathrm{~g} \mathrm{~kg}^{-1} \mathrm{GG}$. The CF-GG mixture was prepared by mixing the CF gel $\left(100 \mathrm{~g} \mathrm{~kg}^{-1}\right)$ with 0 , $2.5,5.0$ or $7.5 \mathrm{~g} \mathrm{~kg}^{-1} \mathrm{GG}$.

\section{Preparation of the mayonnaise}

The recipes and preparation method of the mayonnaise were modified from the procedures of Ma et al. ${ }^{12}$ The recipes of the FF mayonnaise as control and the LF counterpart are shown in Table 1. First, egg yolk and apple vinegar were mixed in a plastic beaker and blended using a mixer (HD-0025, Yeong Jyi Co., Taiwan) at $4 \times g$ for $10 \mathrm{~s}$. Other ingredients (including fat replacers) except oil were then added and stirred at $38 \times g$ for $1 \mathrm{~min}$. Finally, the soybean oil was added slowly (flow rate

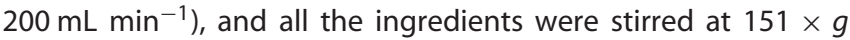
for $2 \mathrm{~min}$. Mayonnaises were transferred to a plastic sealed jar and stored at room temperature (about $25-30^{\circ} \mathrm{C}$ ) until further analyses.

\section{Composition analysis}

Moisture, protein, and ash contents were determined according to $\mathrm{AOAC}^{13}$ official methods. Fat content was determined by Marshall's method. ${ }^{14}$ Carbohydrates were determined by subtracting the sum of percentages of moisture, protein, fat, and ash from $100 \%$. Dietary fiber was determined using the Warrand method. ${ }^{7}$

\section{pH, water activity $\left(\boldsymbol{A}_{\mathrm{w}}\right)$ and brightness measurements}

$\mathrm{pH}$ and $A_{\mathrm{w}}$ values were measured at a temperature of $25^{\circ} \mathrm{C}$ using a $\mathrm{pH}$ meter (Dinslaken) and an Aqualab water activity meter (Decagon Devices, Pullman, WA, USA), respectively. Brightness measurements (Hunter L) were analyzed using an ND-300A chromameter (Nippon Denshoku, Tokyo, Japan). The instrument was standardized before each measurement with white ceramic plates.

\section{Optical microscope observation}

The glass microscope slide was coated with a mayonnaise sample and placed on the stage of an optical microscope (Olympus cx-41, Tokyo, Japan) to obtain photomicrographs.

\section{Scanning electron microscopy (SEM)}

The sample preparation was according to the procedure of Egelandsdal et al. ${ }^{15}$ Samples were coated with gold before obtaining the micrographs. Microscopy utilized a JSM-6300 scanning electron microscope (JEOL, Tokyo, Japan) at $15 \mathrm{kV}$ and a magnification of $3500 \times$.

\section{Particle size measurement}

A Mastersizer 2000 (Malvern Instruments Ltd, Malvern, UK) was used to determine the particle size distribution. Samples were diluted with $1 \mathrm{~g} \mathrm{~kg}^{-1}$ sodium dodecyl sulfate (SDS). The relative index of sample to corn oil was set at 1.460 and the absorption was set at 0.00 . The mean particle size was recorded as the $D(4,3)$ diameter. $^{16}$

\section{Rheology analysis}

The rheological measurements were performed in a rheometer (AR-2000ex, TA Instruments, Crawley, UK). The mayonnaise flow properties at $25^{\circ} \mathrm{C}$ were analyzed using a parallel stainless steel plate with a diameter of $40 \mathrm{~mm} .{ }^{9} \mathrm{~A}$ thixotropic loop measurement was carried out by first increasing the shear rate logarithmically from 0 to $150 \mathrm{~s}^{-1}$ for $4 \mathrm{~min}$, then maintaining it at $150 \mathrm{~s}^{-1}$ for $4 \mathrm{~min}$, and finally decreasing it logarithmically back to $0 \mathrm{~s}^{-1}$ for $2 \mathrm{~min}$. The shear stress, viscosity, flow behavior index and thixotropy data were obtained by using the Herschel-Bulkley equation model as follows:

$$
\tau=\tau_{\mathrm{y}}+K \times \gamma^{n}
$$

where $\tau$ is the shear stress $(\mathrm{Pa}), \tau_{\mathrm{y}}$ is the yield stress $(\mathrm{Pa}), \gamma^{n}$ is the shear rate $\left(\mathrm{s}^{-1}\right), K$ is the consistency index $\left(\mathrm{Pa} \mathrm{s}^{n}\right)$ and $n$ is the flow index.

\section{Sensory analysis}

Sensory evaluation was conducted on the samples after one-day storage at room temperature. Sensory analyses, i.e. appearance, aroma, taste, greasiness and overall acceptability, were carried out by 30 trained panelists. A nine-point hedonic scale was used with $1=$ dislike extremely, $9=$ like extremely. The sample presentation order was randomized. ${ }^{17}$

\section{Statistical analysis}

All experiments were replicated three times. Data were subjected to analysis of variance (ANOVA). Comparison of means used Duncan's multiple range test. Differences of $P<0.05$ were considered to be significant. All analyses were performed using SAS (1985) for Windows.

\section{RESULTS AND DISCUSSION}

A preliminary experiment measuring rheological properties of LF mayonnaise indicated that a single polysaccharide gum, i.e. $X G$ or $C F$, offered good emulsification (data not shown), but neither XG nor CF significantly achieved the rheological properties of the control mayonnaise (FF). Therefore, we evaluated other ingredients to improve flow properties of LF mayonnaise. 

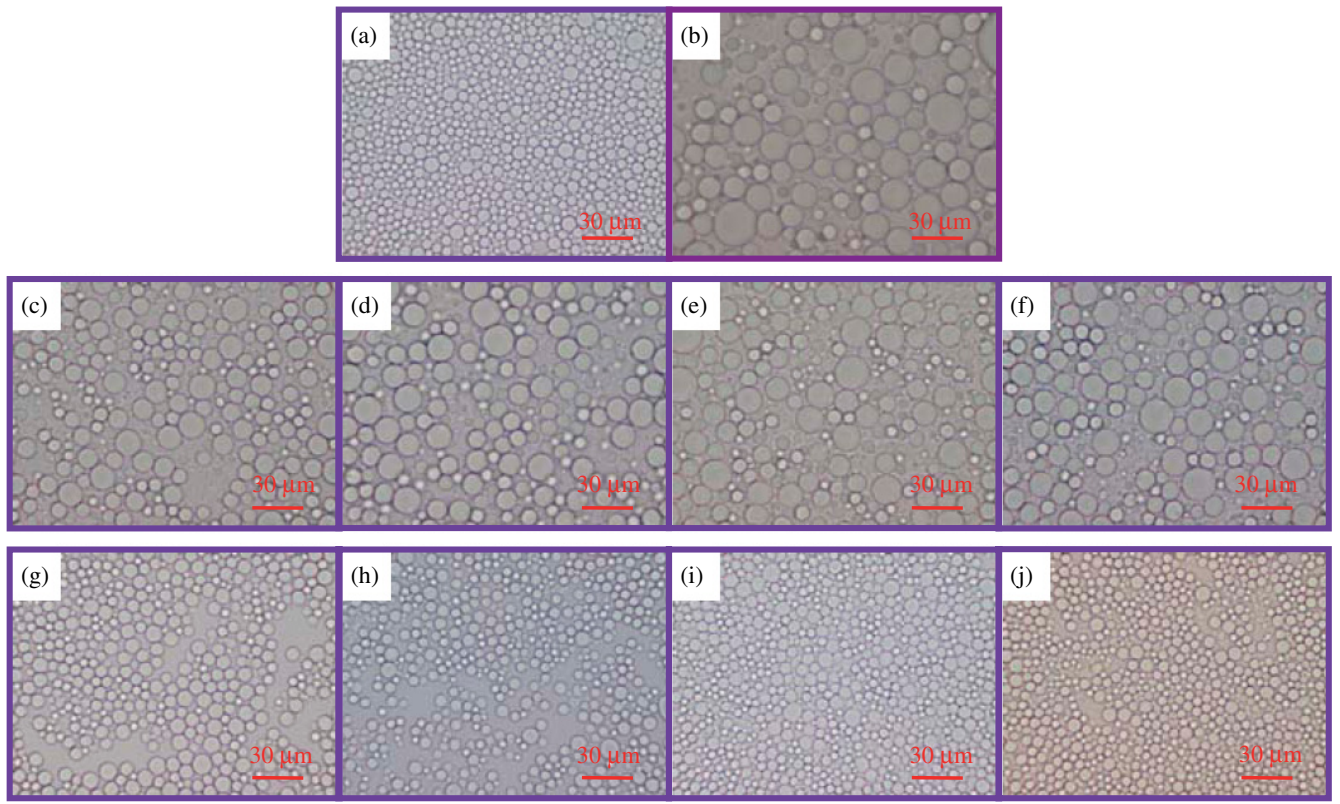

Figure 1. Micrographs by optical microscope of low-fat mayonnaise with different polysaccharide gums: (a) control (FF); (b) $X G$; (c) $X G+5 \mathrm{~g} \mathrm{~kg}^{-1} \mathrm{GG}$; (d) XG + 7.5 g kg-1 GG; (e) XG + $10 \mathrm{~g} \mathrm{~kg}^{-1} \mathrm{GG}$; (f) XG + $12.5 \mathrm{~g} \mathrm{~kg}^{-1} \mathrm{GG}$; (g) CF; (h) CF $+2.5 \mathrm{~g} \mathrm{~kg}^{-1} \mathrm{GG}$; (i) CF $+5 \mathrm{~g} \mathrm{~kg}^{-1} \mathrm{GG}$; (j) CF + $7.5 \mathrm{~g} \mathrm{~kg}$ - $\mathrm{GG}$.

Mayonnaise is an emulsification product with low $\mathrm{pH}$. GG is a neutral gum and does not affect the $\mathrm{pH}$ of food products. In addition, aqueous viscosity can be increased in mixtures of GG and XG. ${ }^{5,18}$ The effects of different concentrations of $G G$ with either $X G$ or CF on quality characteristics were evaluated in this study.

\section{Optical microscope observation}

Figure 1 showed micrographs by optical microscope of LF mayonnaise with different polysaccharide gums. It showed that the oil droplets size of the XG + GG groups were nearly between 3-25 $\mu \mathrm{m}$ and apparently larger than the FF control (Fig. 1(a)-(f)). However, the oil droplets were in a close order and sizes of the CF + GG groups were similar to the FF control (Fig. 1(a), (g)-(j)), between 3 and $13 \mu \mathrm{m}$. The addition of GG did not change the oil droplet size and dispersion in any LF group. It was reported that GG could change the flow equation parameters in LF groups but could not influence the oil droplets sizes. ${ }^{19}$ Probably, no changes in the dispersal situation of LF mayonnaises by adding GG was due to formation of three-dimensional networks between $X G$ and GG, or CF and GG. Liu et al. ${ }^{9}$ found that oil droplets were more rare in LF mayonnaise with low-methoxy pectin as fat replacer than in control mayonnaise. Weak-gel additives poorly disperse in solution, thus inducing a large particle size. The XG exhibits weak gel characteristics, ${ }^{20}$ so that all XG + GG groups had larger, less dispersed oil droplets (Fig. 1(b)-(f)).

\section{Rheological characteristics}

The sample flow curves are presented in Fig. 2. All mayonnaise samples exhibited shear thinning and thixotropic behaviors over the whole range of shear rate studied $\left(0-150 \mathrm{~s}^{-1}\right)$, where segments of the down curves represent values of shear stress lower than those of the up curves at the same point of each shear rate. Data also showed that the higher the shear stress, the higher the GG concentration, and that the increase in rate of shear stress gradually slowed as shearing speed increased.
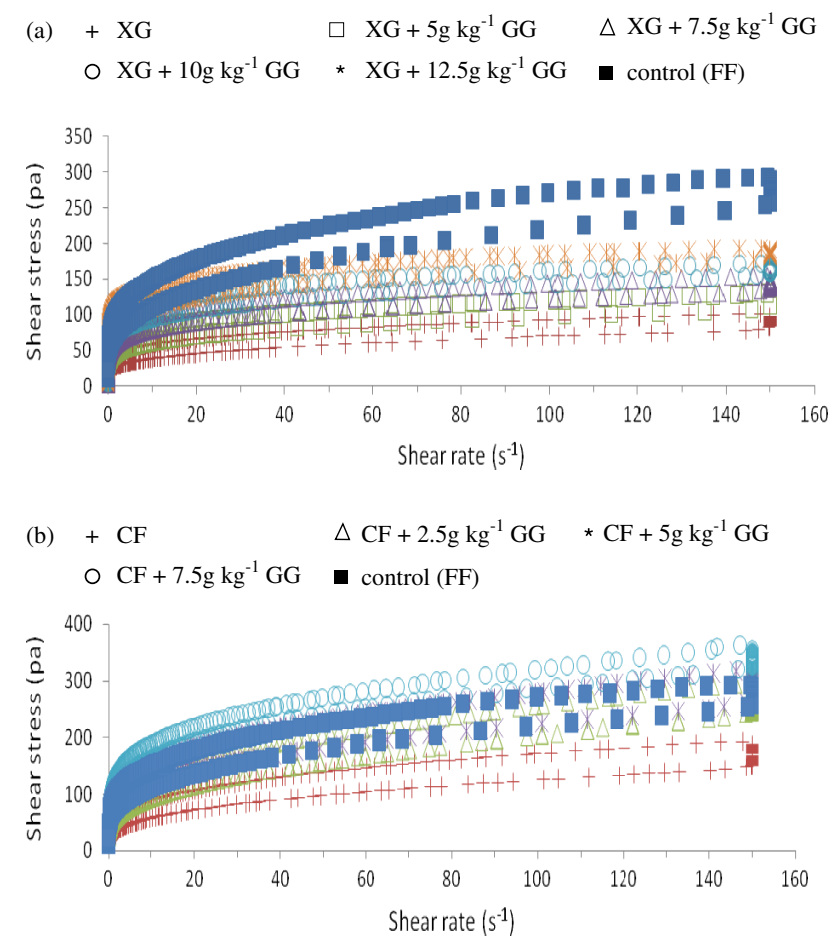

Figure 2. Flow curves for low-fat mayonnaise with (a) $15 \mathrm{~g} \mathrm{~kg}^{-1}$ xanthan gum; +, XG; $\square, X \mathrm{XG}+5 \mathrm{~g} \mathrm{~kg}^{-1} \mathrm{GG} ; \triangle, \mathrm{XG}+7.5 \mathrm{~g} \mathrm{~kg}^{-1} \mathrm{GG} ; \mathrm{O}, \mathrm{XG}+10 \mathrm{~g}$ $\mathrm{kg}^{-1} \mathrm{GG} ;{ }^{*}, \mathrm{XG}+12.5 \mathrm{~g} \mathrm{~kg}^{-1} \mathrm{GG}$; , control (FF); (b) $100 \mathrm{~g} \mathrm{~kg}^{-1}$ citrus fiber and various concentrations of guar gum;,$+ \mathrm{CF} ; \square, \mathrm{CF}+2.5 \mathrm{~g} \mathrm{~kg}^{-1} \mathrm{GG}$; *, $\mathrm{CF}+5 \mathrm{~g} \mathrm{~kg}^{-1} \mathrm{GG} ; \mathrm{O}, \mathrm{CF}+7.5 \mathrm{~g} \mathrm{~kg}^{-1} \mathrm{GG} ; \mathbf{\square}$, control (FF).

To identify the flow characteristics of the mayonnaise samples, the flow curves were fitted to the Herschel-Bulkley equation, as summarized in Table 2 . The results represented that the yield stress $\left(\tau_{y}\right)$ of mayonnaise with XG or CF individually was increased markedly by adding GG. However, $\tau_{y}$ was reduced in mayonnaise 
Table 2. Flow parameter values of low-fat mayonnaise with different polysaccharide gums

\begin{tabular}{lllll} 
Sample & \multicolumn{1}{c}{$\tau_{y}$} & \multicolumn{1}{c}{$K$} & \multicolumn{1}{c}{$n$} & Thixotropy \\
\hline Control $(\mathrm{FF})^{\mathrm{a}}$ & $43.64 \pm 5.31 \mathrm{c}$ & $49.37 \pm 7.20 \mathrm{~cd}$ & $0.33 \pm 0.03 \mathrm{cde}$ & $6446 \pm 582.1 \mathrm{a}$ \\
$\mathrm{XG}$ & $38.28 \pm 5.56 \mathrm{c}$ & $8.03 \pm 1.66 \mathrm{~h}$ & $0.42 \pm 0.05 \mathrm{a}$ & $3289 \pm 27.1 \mathrm{c}$ \\
$\mathrm{XG}+5 \mathrm{~g} \mathrm{~kg}^{-1} \mathrm{GG}$ & $53.35 \pm 5.37 \mathrm{ab}$ & $12.53 \pm 1.00 \mathrm{~h}$ & $0.36 \pm 0.01 \mathrm{~b}$ & $2854 \pm 352.8 \mathrm{c}$ \\
$\mathrm{XG}+7.5 \mathrm{~g} \mathrm{~kg}^{-1} \mathrm{GG}$ & $58.19 \pm 0.77 \mathrm{a}$ & $21.29 \pm 2.32 \mathrm{~g}$ & $0.31 \pm 0.02 \mathrm{de}$ & $3086 \pm 170.7 \mathrm{c}$ \\
XG $+10 \mathrm{~g} \mathrm{~kg}^{-1} \mathrm{GG}$ & $44.70 \pm 5.62 \mathrm{c}$ & $45.85 \pm 3.22 \mathrm{~d}$ & $0.20 \pm 0.02 \mathrm{f}$ & $2893 \pm 271.2 \mathrm{c}$ \\
XG $+12.5 \mathrm{~g} \mathrm{~kg}^{-1} \mathrm{GG}$ & $47.02 \pm 3.79 \mathrm{bc}$ & $63.80 \pm 3.55 \mathrm{~b}$ & $0.16 \pm 0.01 \mathrm{f}$ & $3165 \pm 433.8 \mathrm{c}$ \\
$\mathrm{CF}$ & $24.96 \pm 5.76 \mathrm{~d}$ & $29.63 \pm 6.78 \mathrm{f}$ & $0.35 \pm 0.04 \mathrm{bcd}$ & $6311 \pm 2020.9 \mathrm{a}$ \\
$\mathrm{CF}+2.5 \mathrm{~g} \mathrm{~kg}^{-1} \mathrm{GG}$ & $43.33 \pm 0.95 \mathrm{c}$ & $37.40 \pm 5.43 \mathrm{e}$ & $0.38 \pm 0.02 \mathrm{ab}$ & $7321 \pm 349.5 \mathrm{a}$ \\
$\mathrm{CF}+5 \mathrm{~g} \mathrm{~kg}^{-1} \mathrm{GG}$ & $42.75 \pm 5.91 \mathrm{c}$ & $54.25 \pm 0.78 \mathrm{c}$ & $0.32 \pm 0.01 \mathrm{cde}$ & $7567 \pm 781.7 \mathrm{a}$ \\
$\mathrm{CF}+7.5 \mathrm{~g} \mathrm{~kg}^{-1} \mathrm{GG}$ & $41.56 \pm 1.57 \mathrm{c}$ & $76.43 \pm 2.91 \mathrm{a}$ & $0.28 \pm 0.01 \mathrm{e}$ & $4621 \pm 360.4 \mathrm{~b}$
\end{tabular}

Average of mean vales \pm standard deviation mean vales.

Means in a column followed by different letters are significantly different $(P<0.05)$.

a The mean control was full-fat mayonnaise.

Table 3. Chemical composition analysis $\left(\mathrm{g} \mathrm{kg}^{-1}\right)$ and caloric values of low-fat mayonnaise with different polysaccharide gums at optimum ratios

\begin{tabular}{|c|c|c|c|c|c|c|c|c|}
\hline \multirow[b]{2}{*}{ Samples } & \multirow[b]{2}{*}{ Moisture content } & \multirow[b]{2}{*}{ Fat } & \multirow[b]{2}{*}{ Carbohydrate } & \multirow[b]{2}{*}{ Protein } & \multirow[b]{2}{*}{ Ash } & \multicolumn{2}{|c|}{ Dietary fiber ${ }^{b}$} & \multirow[b]{2}{*}{ Caloric values $^{\mathrm{a}}$} \\
\hline & & & & & & Soluble & Insoluble & \\
\hline Control $^{\mathrm{C}}$ & $165.6 \pm 1.8 c$ & $765.9 \pm 2.5 a$ & $35.2 \pm 1.3 c$ & $22.1 \pm 0.6 a$ & $11.7 \pm 0.5 a$ & & & $7118.4 \pm 20.6 a$ \\
\hline$X G+10 \mathrm{~g} \mathrm{~kg}^{-1} \mathrm{GG}$ & $523.0 \pm 1.1 a$ & $399.2 \pm 6.5 b$ & $43.9 \pm 4.5 b$ & $21.4 \pm 0.6 a$ & $12.5 \pm 0.8 a$ & 6.8 & & $3853.9 \pm 39.6 c$ \\
\hline $\mathrm{CF}+5 \mathrm{~g} \mathrm{~kg}^{-1} \mathrm{GG}$ & $493.7 \pm 1.6 b$ & $401.9 \pm 3.2 b$ & $69.7 \pm 3.0 \mathrm{a}$ & $22.3 \pm 1.7 a$ & $12.4 \pm 0.7 a$ & 15.0 & 13.7 & $3984.8 \pm 20.7 b$ \\
\hline
\end{tabular}

with XG when the amount of GG exceeded $7.5 \mathrm{~g} \mathrm{~kg}^{-1}$. The consistency coefficient $(K)$ values were also markedly increased by addition of $7.5,10.0$ or $12.5 \mathrm{~g} \mathrm{~kg}^{-1}$. These findings are in agreement with the results of Chen, ${ }^{20}$ who indicated that GG increases the aqueous viscosity in a XG mixture. On the contrary, flow behavior index $(n)$ values decreased as the concentration of GG increased. An increased level of thixotropy corresponds to a progressive breakdown of the products' structure as the time of shear is increased. ${ }^{21}$ Our data demonstrated that thixotropy was not affected by adding GG, but it was lower $(P<0.05)$ than in the FF control. Liu et al. ${ }^{9}$ used the combination of whey protein isolate and pectin as fat replacers in LF mayonnaise. They reported that thixotropy was greater in FF mayonnaise compared to the LF counterparts. Our results were similar.

In CF + GG groups, similarities to XG + GG groups were observed $(P>0.05)$. The $K$ values increased as the concentration of $\mathrm{GG}$ increased, but $n$ was decreased at the highest GG concentration. There were no significant differences for flow parameters between treatments with CF $+5 \mathrm{~g} \mathrm{~kg}^{-1} \mathrm{GG}$ and FF control, while $n$ values were similar to those of $X G+G G$ groups. According to the results of appearance (data not shown), oil droplet size and rheological characteristics (Fig. 1 and Table 2), the XG $+10 \mathrm{~g} \mathrm{~kg}^{-1} \mathrm{GG}$ and the $\mathrm{CF}+5 \mathrm{~g} \mathrm{~kg}^{-1} \mathrm{GG}$ were chosen to be the best formulations of LF mayonnaise for further analyses.

\section{Chemical composition and caloric values}

The composition analysis and caloric values of control (FF) and LF mayonnaise containing different polysaccharide gums at optimum ratios are listed in Table 3. Due to high moisture content of fat replacers in the preparation, the moisture content increased with addition of fat replacers, which is a typical characteristic of carbohydrate-based fat replacers. ${ }^{22}$ There were no significant differences between the LF (XG $+10 \mathrm{~g} \mathrm{~kg}^{-1} \mathrm{GG}$ and CF $+5 \mathrm{~g}$ $\mathrm{kg}^{-1} \mathrm{GG}$ ) and control group in ash and protein concentrations. The caloric values of the LF samples were significantly $(P<0.05)$ reduced, because water is a main component of fat replacers, and XG, GG and CF are non-caloric because they are not digested or absorbed in the human digestive tract.

In this study, we used polysaccharide gums which contain a high level of dietary fiber as fat replacers. Hence dietary fiber contents of the XG $+10 \mathrm{~g} \mathrm{~kg}^{-1} \mathrm{GG}$ and the $\mathrm{CF}+5 \mathrm{~g} \mathrm{~kg}^{-1} \mathrm{GG}$ were $6.8 \mathrm{~g} \mathrm{~kg}^{-1}$ and $28.7 \mathrm{~g} \mathrm{~kg}^{-1}$, respectively. According to the Food and Drug Administration's food labeling law, foods with $2.5-4.9 \mathrm{~g}$ of fiber per serving can be labeled as 'a good source of fiber'. The $\mathrm{LF}$ mayonnaise containing $\mathrm{CF}+5 \mathrm{~g} \mathrm{~kg}^{-1} \mathrm{GG}$ meets this criterion. The LF mayonnaise with XG + GG had good texture and a light appearance, whereas the LF mayonnaise with $C F+G G$ was rough textured, which might result from the higher dietary fiber content.

\section{Physicochemical analyses and microstructure}

The brightness ( $L$ value), $A_{\mathrm{w}}$ and $\mathrm{pH}$ values of the control and LF mayonnaises with different polysaccharide gums at optimum ratios after storage for one day at room temperature are shown in Table 4. The brightness of mayonnaise has a major impact on the perceived appearance of the product. ${ }^{17}$ The $L$ values of LF-treated 


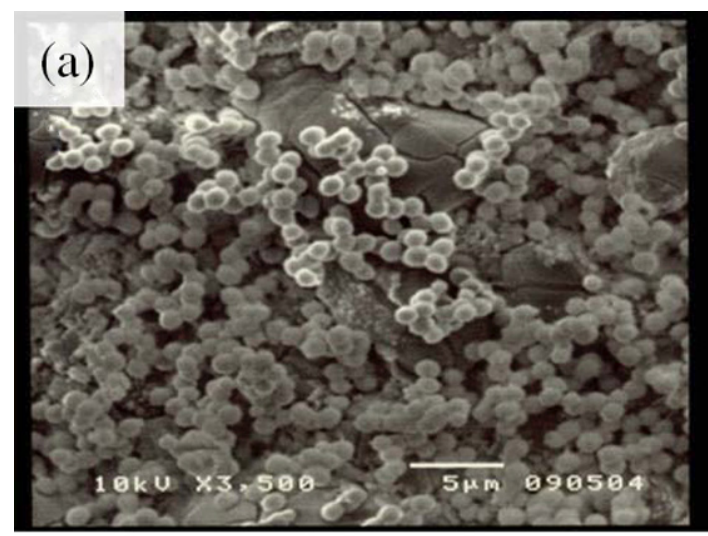

mayonnaises were significantly higher than that of FF control. Chantrapornchai et al..$^{23}$ reported that the emulsion changed from a grey color to an increasingly bright white color as the droplet size decreased due to an increase in light scattering. Hence the higher $L$ values could be related to larger lipid droplets observed in LF mayonnaises with XG + GG and CF + GG (Fig. 1 and Table 4).

The $A_{w}$ of LF mayonnaises increased, as expected, with increased percentage of fat replacers mainly due to the increased of waterholding capacity of the formulations. Chirife et al. ${ }^{24}$ reported that the $A_{w}$ of FF mayonnaises ( $77-79 \%$ oil) was about 0.93 and that of LF samples ( $37-41 \%$ oil) was higher, i.e. close to 0.95 .

According to Hatchcox et al., ${ }^{25}$ the $\mathrm{pH}$ of the fat replacer formulations would be higher than that of the FF formulations due to the dilution of acetic acid in the aqueous phase of the LF formulations. However, the $X \mathrm{G}+10 \mathrm{~g} \mathrm{~kg}^{-1} \mathrm{GG}$ group had a $\mathrm{pH}$ equal to the control (FF) and the CF $+5 \mathrm{~g} \mathrm{~kg}^{-1} \mathrm{GG}$ had a lower $\mathrm{pH}$ than the control (FF). This could be explained by acetic acid residue remaining in the $\mathrm{CF}$ preparation after acid extraction.

A comparison of the structures in various mayonnaises by SEM is shown in Fig. 3. The control (FF) and CF $+5 \mathrm{~g} \mathrm{~kg}^{-1} \mathrm{GG}$ (Fig. 3(a), (c)) mayonnaises had a small and relatively uniform droplet distribution (monodisperse) compared to the $X G+10 \mathrm{~g}$ $\mathrm{kg}^{-1}$ GG group. Gutierrez et al. ${ }^{26}$ illustrated that the viscosity of polydisperse emulsions was significantly lower than that observed in equivalent monodisperse emulsions at the same volume fraction. The oil droplet distribution of CF $+5 \mathrm{~g} \mathrm{~kg}^{-1}$ GG was inclined to monodisperse, and that of $X G+10 \mathrm{~g} \mathrm{~kg}^{-1}$ GG was inclined to polydisperse (Fig. 3). The result was similar to the use of $\beta$-glucan in LF mayonnaises, wherein oil droplets of FF were significantly larger than in this study, perhaps because the homogenization speed was fast. ${ }^{16}$ McClements ${ }^{27}$ reported that the smaller the droplet size, the greater the extent of a three-dimensional gel network with the more open the structure formed at the lower oil volume fractions, leading to larger emulsion viscosity. This phenomenon of oil droplet reticular and network formation can be observed in Fig. 3(b) and (c).

\section{Particle analysis}

Figure 4(a) shows particle size distribution of LF mayonnaise with different polysaccharide gums at optimum ratios. Average diameters of control, $X \mathrm{G}+10 \mathrm{~g} \mathrm{~kg}^{-1} \mathrm{GG}$ and CF $+5 \mathrm{~g} \mathrm{~kg}^{-1} \mathrm{GG}$ were $7.49,12.44$ and $27.78 \mu \mathrm{m}$, respectively. The large diameter of the $\mathrm{CF}+5 \mathrm{~g} \mathrm{~kg}^{-1} \mathrm{GG}$ group results from a second large-sized group of particles (Fig. 4(b)). This was not observed in light or electron micrographs and may result from CF fibers that were not incorporated into the emulsion. The smaller-diameter peak in the $\mathrm{CF}+5 \mathrm{~g} \mathrm{~kg}^{-1} \mathrm{GG}$ group was about the same size as the control (FF)
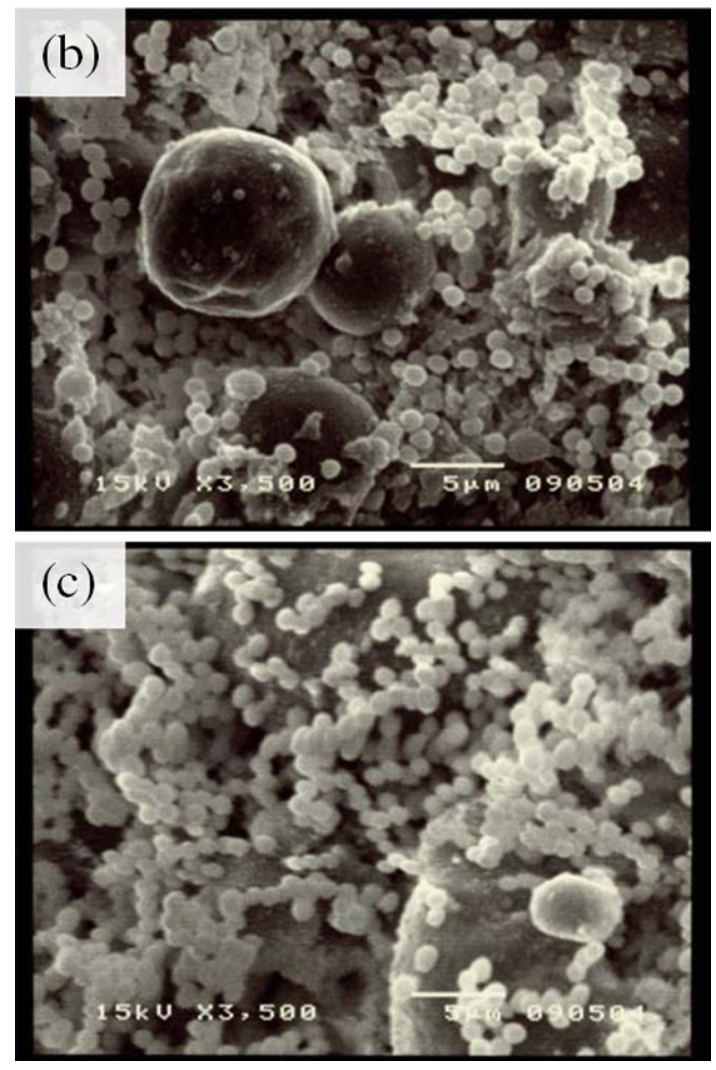

Figure 3. Electron micrographs of low-fat mayonnaise with different polysaccharide gums at optimum ratios: (a) control (FF); (b) XG $+10 \mathrm{~g}$ $\mathrm{kg}^{-1} \mathrm{GG}$; (c) CF $+5 \mathrm{~g} \mathrm{~kg}^{-1} \mathrm{GG}(3500 \times)$.

peak in accordance with the light and SEM micrographs (Figs 1 and 3). Although the particle size of the control (FF) was lower than that of the XG $+10 \mathrm{~g} \mathrm{~kg}^{-1} \mathrm{GG}$ group, there was no difference in $K$ values (Table 2 ). This observation was similar to data from Liu et al. ${ }^{9}$ Moreover, the diameters of oil droplets are only one indicator of the viscosity and emulsion stability. ${ }^{23}$

\section{Sensory evaluations}

Sensory evaluation scores of mayonnaise samples are shown in Fig. 5. The appearance, aroma, taste, greasiness and overall acceptance score of $\mathrm{XG}+10 \mathrm{~g} \mathrm{~kg}^{-1} \mathrm{GG}$ was not $(P>0.05)$ different from the control. However, the scores for appearance, taste and overall acceptance of CF $+5 \mathrm{~g} \mathrm{~kg}^{-1} \mathrm{GG}$ group were lower $(P<0.05)$ than those for the control (FF) and the $\mathrm{XG}$ $+10 \mathrm{~g} \mathrm{~kg}^{-1} \mathrm{GG}$ group. This might be due to the rougher 

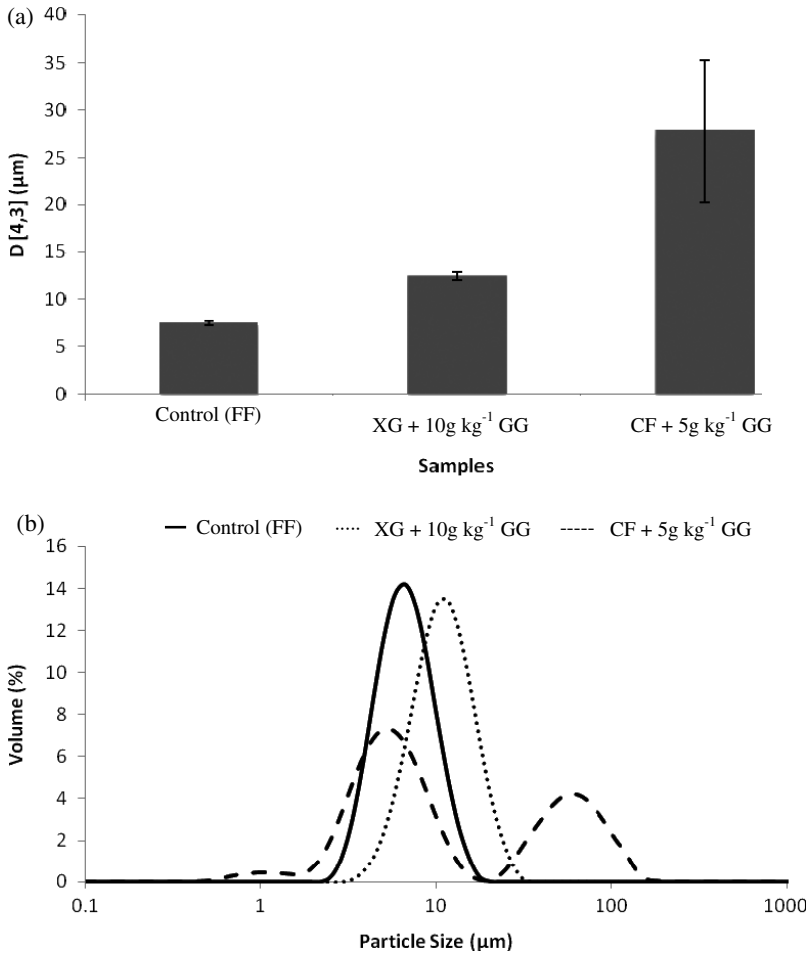

Figure 4. (a) Particle size distribution. (b) Volume mean diameter of low-fat mayonnaise with different polysaccharide gums at optimum ratios.

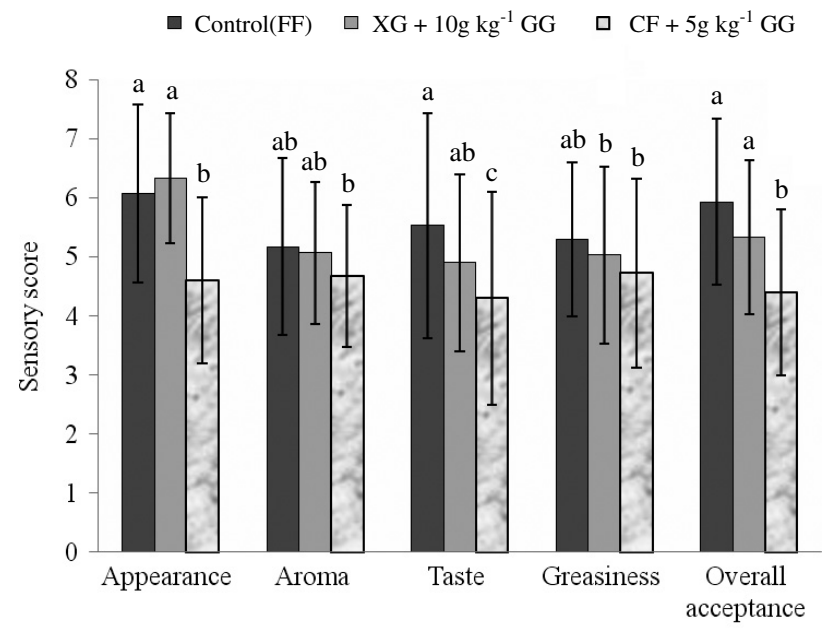

Sensory parameters

Figure 5. Sensory evaluation of mayonnaise samples. Means in columns followed by different letters in the same sensory parameter test are significantly different $(P<0.05)$.

appearance of the CF + GG group compared to other groups (data not shown). In this study, the overall acceptability scores of commercial mayonnaises evaluated by the same sensory panel were approximately 5 (data not shown). Therefore, it is reasonable that the sensory attributes with scores higher than 5 are considered acceptable. The overall acceptance of LF mayonnaises formulated with the XG + $10 \mathrm{~g} \mathrm{~kg}^{-1} \mathrm{GG}$ was 5; hence it was acceptable. On the other hand, the CF content influenced taste and appearance scores so that overall acceptability of CF $+5 \mathrm{~g} \mathrm{~kg}^{-1} \mathrm{GG}$ was lower than other mayonnaise groups. There were no $(P>0.05)$ differences in aroma, greasiness or flow parameter values in the $\mathrm{CF}+5 \mathrm{~g} \mathrm{~kg}^{-1} \mathrm{GG}$ group compared to FF control (Table 2 and Fig. 5). Although the $\mathrm{CF}+5 \mathrm{~g} \mathrm{~kg}^{-1} \mathrm{GG}$ group contains sufficient dietary fiber to be considered as a health food (Table 3), the question remain how to improve the mouthfeel of high-fiber LF mayonnaises.

\section{CONCLUSION}

The objective of this study was to investigate whether XG-GG and CF-GG could be optimized as fat replacers in formulations of LF mayonnaise. The XG $+10 \mathrm{~g} \mathrm{~kg}^{-1} \mathrm{GG}$ and CF $+5 \mathrm{~g} \mathrm{~kg}^{-1}$ GG groups had similar rheological properties to the control (FF) and could approximately halve the caloric values and increase total dietary fiber content (near $3 \mathrm{~g} \mathrm{~kg}^{-1}$ ). They also increased brightness value compared to the control. Scanning electron micrographs showed that the network of aggregated droplets in LF treatments contained a large number of interspaced voids of varying dimensions. The oil droplets were polydispersed in XG + $10 \mathrm{~g} \mathrm{~kg}^{-1} \mathrm{GG}$, whereas they were monodispersed in $\mathrm{CF}+5 \mathrm{~g} \mathrm{~kg}^{-1}$ $\mathrm{GG}$. In the comparison of sensory evaluation of LF treatments with commercial mayonnaises, there were no significant differences in any sensory scores among XG $+10 \mathrm{~g} \mathrm{~kg}^{-1} \mathrm{GG}$ and control. However, there were significant differences in appearance, taste and overall acceptance between $\mathrm{CF}+5 \mathrm{~g} \mathrm{~kg}^{-1} \mathrm{GG}$ and control. Hence $X G+10 \mathrm{~g} \mathrm{~kg}^{-1} \mathrm{GG}$ were further applied to develop as a functional ingredient of LF salad dressings.

\section{REFERENCES}

1 Depree JA and Savage GP, Physical and flavour stability of mayonnaise. Trends Food Sci Technol 12:157-163 (2001).

2 Karas R, Skvarča M and Žlender B, Sensory quality of standard and light mayonnaise during storage. Food Technol Biotechnol 40:119-127 (2002).

3 McClements DJ and Demetriades K, An integrated approach to the development of reduced-fat food emulsions. Crit Rev Food Sci Nutr 38:511-536 (1998).

4 Laneuville SI, Paquin P and Turgeon SL, Formula optimization of a low-fat food system containing whey protein isolate-xanthan gum complexes as fat replacer. Food Sci Nutr 70:513-519 (2005).

5 Ward FM, Hydrocolloid systems as fat mimetics in bakery products: icings, glazes, and fillings. Cereals Foods World 42:386-390 (1997).

6 ADA, Position of the American Dietetics Association: fat replacers. J Am Diet Assoc 105:266-275 (2005).

7 Warrand J, Healthy polysaccharides: the next chapter in food products. Food Technol Biotechnol 44:355-370 (2006).

8 Dolz M, Hernández MJ, Delegido J, Alfaro MC and Muñoz J, Influence of xanthan gum and locust bean gum upon flow and thixotropic behaviour of food emulsions containing modified starch. J Food Eng 81:179-186 (2007)

9 Liu H, Xu XM and Guo SD, Rheological, texture and sensory properties of low-fat mayonnaise with different fat mimetics. LWT Food Sci Technol 40:946-954 (2007).

$10 \mathrm{Ma}$ L and Barbosa-Cánovas GV, Rheological characterization of mayonnaise. Part II: Flow and viscoelastic properties at different oil and xanthan gum concentrations. J Food Eng 25:409-425 (1995).

11 Dervisoglu $M$, The effect of citrus fibre on the physical, chemical and sensory properties of ice cream. Food Sci Technol Int 12:159-164 (2006).

12 Ma Y, Cai C, Wang J and Sun DW, Enzymatic hydrolysis of corn starch for producing fat mimetics. J Food Eng 73:297-303 (2006).

13 AOAC, Official Methods of Analysis of the Association of Analytical Chemists (15th edn). AOAC, Washington, DC (1995).

14 Marshall RT, Standard Methods for the Examination of Dairy Products. American Public Health Association, Washington, DC (1992).

15 Egelandsdal B, Langsrud $\varnothing$, Nyvold T, Sontum PK, Sørensen C, Enersen $G$, et al, Estimating significant causes of variation in emulsions' droplet size distributions obtained by the electrical 
sensing zone and laser low angle light scattering techniques. Food Hydrocoll 15:521-532 (2001).

16 Worrasinchai S, Suphantharika M, Pinjai S and Jamnong P, $\beta$-Glucan prepared from spent brewer's yeast as a fat replacer in mayonnaise. Food Hydrocoll 20:68-78 (2006).

17 Lin CS and Yeh RY, Application and Practice of Sensory Evaluation. Rui Yu, Taipei, Taiwan (2003).

18 Wang Q, Ellis PR and Ross-Murphy SB, The stability of guar gum in an aqueous system under acidic conditions. Food Hydrocoll 14:129-134 (2000).

19 Guo CF, Application of polysaccharide gums in food industry. Baking Ind 117:49-59 (2004).

20 Chen YH, The properties and applications of Xanthan gum. Food Ind 27:24-30 (1995)

21 Abu-Jdayil B, Modelling the time dependant rheological behavior of semi-solid foodstuffs. J Food Eng 57:97-102 (2003).

22 Akoh CC and Min DB, Food Lipids. Marcel Dekker, New York (2002).
23 Chantrapornchai W, Clydesdale F and McClements DJ, Influence of droplet characteristics on the optical properties of colored oil-inwater emulsions. Coll Surf Physicochem Eng Aspects 155:373-382 (1999).

24 Chirife J, Vigo MS, Gómez RG and Favetto GJ, Water activity and chemical composition of mayonnaises. J Food Sci 54:1658-1659 (1989).

25 Hathcox AK, Beuchat LR and Doyle MP, Death of enterohemorrhagic Escherichia coli 0157:H7 in real mayonnaise and reduced-calorie mayonnaise dressing as influenced by initial population and storage temperature. Appl Environ Microbiol 61:4172-4177 (1995).

26 Gutierrez X, Siliva F, Chirinos M, Leiva J and Rivas H, Bitumen-in-water emulsion: an overview on formation, Stability and rheological properties. J Dispers Sci Technol 23:405-418 (2002).

27 McClements DJ, Food Emulsions: Principles, Practice and Techniques. CRC Press, Boca Raton, FL, pp. 243-254 (1999). 